\title{
ELECTROCHEMICAL SENSORS AS SIMPLE AND CHEAP DEVICES FOR RAPID DETERMINATION OF VARIOUS SPECIES IN ENVIRONMENTAL SAMPLES
}

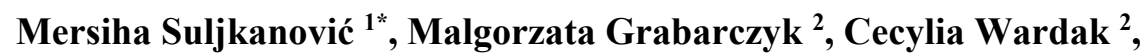 \\ Marzena Adamczyk ${ }^{2}$, Karolina Pietrzak ${ }^{2}$ \\ ${ }^{1}$ University of Tuzla, Faculty of Natural Sciences and Mathematics, Department of Chemistry, Univerzitetska 4, \\ 75000 Tuzla, Bosnia and Herzegovina \\ ${ }^{2}$ Maria Curie-Sklodowska University, Faculty of Chemistry, Department of Analytical Chemistry and \\ Instrumental Analysis, Maria Curie-Sklodowska Sq. 3, 20-031 Lublin, Poland \\ *E-mail of corresponding author: mersiha.suljkanovic@untz.ba
}

\begin{abstract}
The electrochemical methods are very good tool for determination of trace concentrations of various species in water samples. The analysis carried out using these methods are usually simple, fast and also the cost of the required equipment is much lower comparing to other instrumental methods. Furthermore, the electroanalytical methods are easy to automate and computerize. Among five major groups of these methods (potentiometry, voltammetry, coulometry, conductometry and dielectrometry), potentiometry and voltammetry attract the greatest attention of researchers. In this paper, experimental results of research related to development of procedures (voltammetric and potentiometric) for the determination of elements in environmental water samples were presented. Due to their common occurrence in environment and possible toxic effects on living organisms, vanadium and nitrate ions were selected for investigation. Optimization of voltammetric procedure for $V(V)$ determination were carried out in matrix containing different surfactants and humic acids, using lead film electrode as a working electrode. Results showed that only nonionic surfactant Brij-35 did not interfere with the voltammetric signal. Other surfactants as well as humic acids reduced the signal, and possibility of their elimination with suitable resins were also investigated. Potentiometric measurements were consisted of preparation and determination of analytical properties of nitrate ion-selective electrodes with solid contact. The results showed that among three different membrane composition, the best response was achieved by membrane containing: Ni(Phen) $)_{2}$ THTDPCl, PVC and NPOE in the ratio of 1:2:33:64 wt. \%, respectively. With the detection limit of $2.8 \times 10^{-6} \mathrm{~mol} \mathrm{~L} L^{-1}$, the working concentration range from $5 \times 10^{-5}$ to $1 \times 10^{-1} \mathrm{~mol} \mathrm{~L}^{-1}$ and a slope of $-55.1 \mathrm{mV}$ per decade, this electrode showed good selectivity to sulfate, acetate, carbonate, dihydrogen phosphate, fluoride and chloride ions, and also good potential reversibility.
\end{abstract}

Keywords: voltammetry, lead film electrode, vanadium, potentiometry, nitrate ion-selective electrode

Received: 04.04.2019. / Accepted: 28.05.2019.

Published online: 16.07.2019.

Original scientific paper

\section{INTRODUCTION}

For determination of trace level of elements in environmental samples, electrochemical methods are very good tool. Simple and fast procedures, as well as the lower prices of required instruments, make these methods more attractive comparing to others. Among five different types of electrochemical methods (potentiometry, voltammetry, coulometry, conductometry and dielectrometry), potentiometry and voltammetry attract the greatest attention of researchers.

Stripping voltammetry and its use for the determination of $V(V)$

Stripping voltammetry (SV) is a very sensitive and rapid method for the analysis of trace concentrations of different ions in the solution. Extremely low limits of detection $\left(10^{-10}\right.$ to $\left.10^{-12} \mathrm{~mol} \mathrm{~L}^{-1}\right)$ can be obtained using this method. High sensitivity of SV is a result of the fact that the single measurement consists of two steps. During the first step, analyzed ions are deposited onto an electrode surface. This is followed by the stripping step and the peak registered on the voltammogram is directly proportional to the concentration of analyte in the solution. Depending on the nature of preconcentration and stripping steps, stripping voltammetry can be divided into: anodic stripping voltammetry (ASV), cathodic stripping voltammetry (CSV) and adsorptive stripping voltammetry (AdSV). Besides the excellent sensitivity, these techniques also offer: multielement and speciation capabilities, possibility for automated online and in situ measurements and utilize low-cost instrumentations. These techniques are widely used for testing drinking water quality (tap water), sewage and environmental water (Zosky 2007; Settle 1997). During the development of voltammetric procedures, the key element is the selection of the working electrode on which the accumulation of the determined ions takes place. Some of the first and also the most popular electrodes used in voltammetric procedures were mercury electrodes. Now with the growing awareness of the mercury's toxicity, there is a need for new less-toxic sensors. One of such sensors that has been introduced in the replacement 
of mercury electrodes is a lead film electrode (PbFE) (Grabarczyk \& Wasąg 2016; Grabarczyk \& Wasąg 2015; Wasąg \& Grabarczyk 2016).

This paper describes the voltammetric procedure for determination of $\mathrm{V}(\mathrm{V})$ in natural water samples with organic substances in matrix, such as surface active substances and humic substances. The procedure is based on adsorptive stripping voltammetry, the essence of which is the adsorptive accumulation of $\mathrm{V}(\mathrm{V})$-cupferron complexes on the in situ obtained lead film electrode used as a working electrode. Vanadium was selected for this investigation due to its common occurrence in environment and possible toxic effects on living organisms. Vanadium is a heavy metal whose occurrence is usually associated with natural processes in the environment (weathering of rocks, soil erosion and volcanic emissions). Anthropogenic release of vanadium into the environment is mainly related to industrial sources, especially oil refineries and power plants using heating oil and vanadium-rich coal. Vanadium occurs in three oxidation states in the environment $(+\mathrm{III},+\mathrm{IV},+\mathrm{V})$, but $\mathrm{V}(\mathrm{V})$ is of greater toxicity and in higher concentrations negatively affects plants, animals and humans. Therefore, determination of $\mathrm{V}(\mathrm{V})$ in environmental samples is necessary from the point of view of environmental protection (Mampuru et al. 2015; Xiao et al. 2015). Considering the fact that the proposed voltammetric procedure is intended for the determination of $V(V)$ in environmental samples, the influence of surface active substances and humic substances on the vanadium signal was examined. The choice of these substances was favored by the fact that they are the main components in the matrix of real samples. Since these compounds caused suppression of the vanadium voltammetric signal, it was proposed to reduce these interferences by pre-mixing the sample with an Amberlite type resin. During this mixing, surfactants and humic substances were adsorbed on the resin while vanadium ions remained in the solution which is introduced into the volumetric measuring cell.

Potentiometry and its use for the determination of nitrates

Potentiometry with ion-selective electrodes (ISEs) is known as an excellent low-cost analytical technique for selective, sensitive and rapid determination of vast variety of analytes in clinical, environmental and industrial samples (Wardak 2014; Plaza et al. 2005). Among different types of ISEs, special attention was focused on ionselective electrodes with polymer membrane without the internal electrolyte, called Solid Contact Ion-selective Electrodes (SCISEs). These electrodes have many advantages over their classical equivalents containing an internal solution (Wardak 2012). The lack of the internal solution enables construction of electrodes which can have any shape and much smaller sizes, so consequently their production costs can be reduced. The solid contact electrodes are especially useful in measurements performed in outdoor conditions, outside the laboratory, because they are highly resistant to damage and also simple in use and transport. Besides, the SCISEs are often characterized by a lower limits of detection, due to the elimination of primary ion leaching from the internal solution via the membrane to the near-membrane layer of a sample solution (Sutter et al. 2004). The solid contact ion-selective electrodes can be considered to be the first step to constructing microelectrodes, because, in order to miniaturize ion-selective electrodes it is necessary to eliminate the internal electrolyte solution. In the case of small-sized electrodes, the electrode resistance usually increases, which leads to increased noise and potential instability. The prototype of SCISEs was a "coated wire" type construction in which the ion-selective polymer membrane covered the platinum wire (Cattrall \& Freiser 1971). The problem in construction of ion-selective electrodes with solid contact is instability and weak reproducibility of potential due to thermodynamically nondefined phase boundary between the membrane of ionic conductance and the internal electrode of electron conductance (Hulanicki \& Trojanowicz 1976; Hauser et al. 1995). Another reason for a drift of potential in solid contact electrodes is a very thin aqueous layer which is often formed between the polymer membrane and the internal electrode. The composition of this layer undergoes a transformation due to the changes in sample composition and $\mathrm{pH}$, which results in instability of the electrode potential (Fibbioli et al. 2000).

In this paper, preparation and properties of nitrate ion-selective electrodes with solid contact are described. As active membrane component, nickel complex with 1,10-phenanthroline ( $\left.\mathrm{Ni}(\mathrm{Phen})_{2}\right)$ was used. The electrodes were constructed on the basis of $\mathrm{Ag} / \mathrm{AgCl}$ electrode and phosphonium chloride was used as ionic additive and as transducer media. This compound lowers the membrane resistance and maintains constant concentration of chloride ions in the membrane phase surrounding internal $\mathrm{Ag} / \mathrm{AgCl}$ electrode. This paper describes development of potentiometric solid contact sensor for nitrate determination. Nitrates are present in ground and surface waters as a results of their widespread application in the industry and agriculture. The determination of nitrates is very important because of their toxic and carcinogenic effect on humans and animals, connected with reduction of nitrate to nitrite which can take place even in the mouth under the influence of saliva (McKnight et al. 1999).

\section{EXPERIMENTAL PART}

\subsection{Reagents}

For voltammetric procedure, a stock solution of $1 \mathrm{~g} \mathrm{~L}^{-1} \mathrm{~V}(\mathrm{~V})$, cupferron, suprapur $\mathrm{CH}_{3} \mathrm{COOH}$ and $\mathrm{NaOH}$ were obtained from Merck (Darmstadt, Germany). The working solutions of $\mathrm{V}(\mathrm{V})$ of lower concentrations were prepared by dilution of the stock solution by $5 \times 10^{-3} \mathrm{~mol} \mathrm{~L}^{-1}$ of $\mathrm{HNO}_{3}$ as required. A solution of $1 \times 10^{-2} \mathrm{~mol} \mathrm{~L}^{-1}$ of cupferron was prepared daily by dissolving $0.0155 \mathrm{~g}$ of the reagent in water in a $10 \mathrm{~mL}$ volumetric flask. A standard solution of $1 \mathrm{~g} \mathrm{~L}^{-1} \mathrm{~Pb}$ (II), Triton X-100, Brij-35, sodium dodecyl sulfate (SDS) and 
cetyltrimethylammonium bromide (CTAB) were purchased from Fluka (Buchs, Switzerland). Humic acids (HA) and fulvic acids (FA) were obtained from Aldrich. All solutions were prepared using triply distilled water. Amberlite XAD-2 resin and Amberlite XAD-16 resin were obtained from Sigma (St. Louis, MO, USA). The resins were washed four times with triply distilled water and dried up at the temperature of $50{ }^{\circ} \mathrm{C}$.

Potentiometric procedure required chemicals: 2-Nitrophenyl octyl ether (NPOE) (Fluka), Poly(vinyl chloride) low molecular weight (PVC) (Aldrich), Trihexyltetradecylphosphonium chloride (THTDPCl) (Aldrich), 4,7-diphenyl-1,10-phenanthroline (Aldrich). Complex of Ni(II) with 1,10 phenanthroline was obtained in the reaction of $20 \mathrm{~mL}$ of $5 \times 10^{-2} \mathrm{~mol} \mathrm{~L}^{-1}$ aqueous solution of nickel(II) chloride and $20 \mathrm{~mL}$ of $0.15 \mathrm{~mol} \mathrm{~L}^{-1}$ 4,7-diphenyl-1,10-phenanthroline solution in ethyl alcohol. The obtained pink solid was filtered, gently washed with distilled water. All aqueous solutions were prepared with salts of the highest purity available (pure pro analysis) using freshly deionized water.

\subsection{Instrumentation}

Voltammetric measurements were carried out using an Autolab analyzer (Utrecht, The Netherlands). A three electrode system consisting of a glassy carbon (GC) working electrode, a platinum auxiliary electrode and an $\mathrm{Ag} / \mathrm{AgCl}$ reference electrode (filled with $\mathrm{NaCl}$ ), was employed. Before each series of measurements, the glassy carbon electrode of $1 \mathrm{~mm}$ diameter was polished daily on 2000 grit sandpaper using $0.3 \mu \mathrm{m}$ alumina slurry on the Buehler polishing pad.

The measurement of the electromotive force (EMF) of the cell composed of ion-selective electrode and reference electrode Orion 90-02, was carried out at room temperature in a solution stirred with a magnetic stirrer by means of potentiometric system (Lawson Labs. Inc., USA) and IBM PC computer.

\subsection{Procedure}

\subsubsection{Standard voltammetric procedure for vanadium determination}

All voltammetric measurements were carried out in $0.1 \mathrm{~mol} \mathrm{~L}-1$ acetate buffer $(\mathrm{pH}=6.0), 3 \times 10^{-4} \mathrm{~mol} \mathrm{~L}^{-1}$ $\mathrm{Pb}$ (II) and $7 \times 10^{-4} \mathrm{~mol} \mathrm{~L}^{-1}$ cupferron. The experiments were carried out from undeaerated solutions with a volume of $15 \mathrm{~mL}$. The voltammetric procedure consisted of the following main steps:

- $-1.1 \mathrm{~V}$ for $20 \mathrm{~s}$ (lead film electrode $(\mathrm{PbFE})$ was formed on the glassy carbon electrode by the reduction of $\mathrm{Pb}$ (II) to lead metallic state),

- $-0.6 \mathrm{~V}$ for $30 \mathrm{~s}$ (accumulation of $\mathrm{V}(\mathrm{V})$-cupferron complexes on $\mathrm{PbFE}$ ),

- the potential was scanned from $-0.6 \mathrm{~V}$ to $-0.9 \mathrm{~V}$ (differential pulse stripping voltammogram was recorded corresponding to the reduction of the accumulated complex; the vanadium peak appeared at about $-0.7 \mathrm{~V}$ and was directly proportional to the concentration of $\mathrm{V}(\mathrm{V})$ in the sample).

After each measurement, the electrochemical cleaning of GC electrode was carried out in the following way: $-1.3 \mathrm{~V}$ for $15 \mathrm{~s}$ and $+0.2 \mathrm{~V}$ for $15 \mathrm{~s}$ under stirring. At the potential of $-1.3 \mathrm{~V}$ the remains from previous measurement were reduced to the metallic state and then at the second potential they were stripped from the electrode to the solution.

\subsubsection{Procedure of organic interferences elimination for vanadium determination}

For effective elimination of interferences caused by organic substances commonly found in environmental water samples, $10 \mathrm{~mL}$ of analyzed real sample or a synthetic sample (including $\mathrm{V}(\mathrm{V})$ and optionally organic interferences) was mixed during $5 \mathrm{~min}$. with $0.5 \mathrm{~g}$ XAD-2 (or XAD-16 resin optionally) in the presence of $0.1 \mathrm{~mol} \mathrm{~L}^{-1}$ acetate buffer $\mathrm{pH}=6.0$. After this step, the solution from above the resin was introduced into the voltammetric cell and the voltammetric measurement was performed as described above.

\subsubsection{Preparation of ion-selective electrodes for nitrate determination}

An internal $\mathrm{Ag} / \mathrm{AgCl}$ electrode was prepared from a silver wire which was anodized electrochemically in $\mathrm{HCl}$ solution using voltage source of $5 \mathrm{~V}$ (KABiD-PRESS, Poland). Then the electrode was rinsed with water, dried with tissue-paper, mounted in the Teflon holder and covered by the membrane phase.

The electrode membrane phase was prepared as follows: the membrane components were weighed and thoroughly mixed. The mixture was deareated by means of a vacuum oil pump. The Teflon holder was filled with the mixture and the mixture was gelated at $80-90{ }^{\circ} \mathrm{C}$ for $15 \mathrm{~min}$. During the gelation, plasticization of PVC takes place and as a result membrane phase is in homogeneous polymer state. After cooling to room temperature the sensor was mounted in the electrode body and conditioned for at least 12 hours in $1 \times 10^{-3} \mathrm{~mol} \mathrm{~L}^{-1} \mathrm{NaNO}_{3}$ solution to saturate PVC membrane in nitrate ions. For each membrane composition (presented in Table 2.), three identical electrodes were prepared and subjected to the same studies. 


\section{RESULTS AND DISCUSSION}

\subsection{Influence of surfactants and humic compounds on vanadium determination}

Organic substances occurring in natural samples can interfere with stripping voltammetry analysis mainly by adsorption onto the electrode surface causing a decrease of the peak of the analyzed substance or its total decay. The influence of different types of surface-active substances such as: cationic (CTAB), non-ionic (Triton X-100 and Brij-35), anionic (SDS) and humic compounds such as humic and fulvic acids was studied.

The influence of interferences was tested using a fixed concentration of $5 \times 10^{-8} \mathrm{~mol} \mathrm{~L}^{-1} \mathrm{~V}(\mathrm{~V})$ and different amounts of organic substances using standard procedure of measurement (as described in subsection 2.3.1.). A tolerable limit was defined as the amount of organic substances that produced an error not exceeding $5 \%$ in the peak current of vanadium. Detailed results of the influence of different types of surface active substances and humic substances using a standard procedure are presented in Table 1. As shown in the table, only nonionic surfactant Brij-35 did not show any interfering effect, while others partially decreased the signal (anionic SDS to $75 \%$ ) or totally reduced the signal (nonionic Triton X-100 and cationic CTAB at the amount of 2 ppm). Humic and fulvic acids showed also total interfering effect.

Table 1. The influence of different organic substances on $5 \times 10^{-8} \mathrm{~mol} \mathrm{~L}^{-1} \mathrm{~V}(\mathrm{~V})$ analytical signal using the standard procedure

\begin{tabular}{|c|c|c|}
\hline $\begin{array}{c}\text { INTERFERING } \\
\text { ORGANIC } \\
\text { SUBSTANCE }\end{array}$ & $\begin{array}{c}\text { CONCENTRATION OF } \\
\text { INTERFERENCES } \\
{\left[\mathrm{mg} \mathrm{L}^{-1}\right]}\end{array}$ & $\begin{array}{c}\text { RELATIVE SIGNAL } \\
\text { OF V(V) } \\
\text { IN \% }\end{array}$ \\
\hline CTAB & 1 & 85 \\
& 2 & No signal \\
\hline Triton X-100 & 1 & 65 \\
& 2 & No signal \\
\hline \multirow{2}{*}{ Brij-35 } & 1 & 100 \\
& 2 & 100 \\
\hline \multirow{2}{*}{ SDS } & 1 & 35 \\
& 2 & 20 \\
\hline HA & 5 & No signal \\
\hline \multirow{2}{*}{ FA } & 1 & 50 \\
& 1 & No signal \\
\hline
\end{tabular}

\subsection{Elimination of organic interferences for vanadium determination}

Considering the significant interfering effects of some investigated compounds, the experiments of the elimination of those interferences with appropriate resins were carried out. The measurements were performed as described in subsection 2.4. In the ideal case, interfering compound adsorbs on the resin surface, whereas $V(V)$ remains quantitatively in the solution. The main challenge here is to choose such measurement conditions that would provide the highest sensitivity of determinations and at the same time the greatest effectiveness in removing the interferences. The results showed that:

- resin Amberlite XAD-16 eliminates CTAB interfering effect to certain point: the signal decreased to $25 \%$ at $2 \mathrm{ppm}$ (not the total reduction of signal which happened without resin);

- resin Amberlite XAD-2 eliminate Triton-X100 interfering effect to certain point: the signal decreased to $85 \%$ at $2 \mathrm{ppm}$ (not the total reduction of signal which happened without resin);

- 5 ppm of SDS does not affect at all the vanadium signal in the presence of Amberlite XAD-2 nor XAD-16 for humic and fulvic acids, application of resins did not yield a sufficient elimination effect.

\subsection{Potentiometric response of prepared nitrate-selective electrodes}

For different composition of each electrode membrane phase, the analytical parameters such as the limit of detection, the linear concentration range and characteristic slope were determined and listed in Table 2. The potential response of prepared electrodes was measured in sodium nitrate solutions in concentration range from 1 $\times 10^{-6}$ to $1 \times 10^{-1} \mathrm{~mol} \mathrm{~L}^{-1}$. The obtained calibration curves are presented in Figure 1 .

Electrode response obviously depends on the membrane composition. The sensor no. 1 with blanc membrane without active substance and ionic additive did not respond to nitrate ions and exhibited poor cationic response, while electrode no. 2 containing in the membrane $1 \% \mathrm{wt}$. $\mathrm{Ni}(\mathrm{Phen})_{2}$ showed anionic response with sensitivity of $-44.0 \mathrm{mV} /$ decade. In the case of electrode with membrane composition no. 3 incorporating Ni(Phen) $)_{2}$ THTDPCl, PVC and NPOE in the ratio of 1:2:33:64 wt. \%, respectively, the best anionic response was achieved. The detection 
limit of electrode no. 3 was $2.8 \times 10^{-6} \mathrm{~mol} \mathrm{~L}^{-1}$ and the working concentration range was from $5 \times 10^{-5}$ to $1 \times 10^{-1}$ mol L ${ }^{-1}$ with a slope of $-55.1 \mathrm{mV}$ per decade. As a result, electrode no. 3 was chosen for selectivity and reversibility studies.

Table 2. Membrane composition and electrodes performances

\begin{tabular}{|c|c|c|c|c|c|c|c|}
\hline \multirow[b]{2}{*}{ 之望 } & \multicolumn{4}{|c|}{ MEMBRANE COMPOSITION } & \multirow[b]{2}{*}{$\begin{array}{c}\text { LIMIT OF } \\
\text { DETECTION } \\
{\left[\mathrm{mol} \mathrm{L}^{-1}\right]}\end{array}$} & \multirow[b]{2}{*}{$\begin{array}{c}\text { SLOPE } \\
{[\mathrm{mV} / \text { decade }]}\end{array}$} & \multirow[b]{2}{*}{$\begin{array}{c}\text { MEASURING } \\
\text { RANGE } \\
{\left[\mathrm{mol} \mathrm{L}^{-1}\right]}\end{array}$} \\
\hline & $\begin{array}{c}\mathrm{Ni}(\text { Phen })_{2} \mathrm{Cl} \\
2 \\
{[\mathrm{mg}]}\end{array}$ & $\begin{array}{c}\text { THTDPCl } \\
{[\mathrm{mg}]}\end{array}$ & $\begin{array}{l}\text { PVC } \\
{[\mathrm{mg}]}\end{array}$ & $\begin{array}{c}\mathrm{NPOE} \\
{[\mathrm{mg}]}\end{array}$ & & & \\
\hline 1 & - & - & 330 & 670 & \multicolumn{3}{|c|}{ poor anionic response } \\
\hline 2 & 10 & - & 330 & 660 & $3.3 \times 10^{-5}$ & -44.0 & $1.0 \times 10^{-4}-1.0 \times 10^{-1}$ \\
\hline 3 & 10 & 20 & 330 & 640 & $1.0 \times 10^{-6}$ & -55.1 & $5.0 \times 10^{-5}-1.0 \times 10^{-1}$ \\
\hline
\end{tabular}

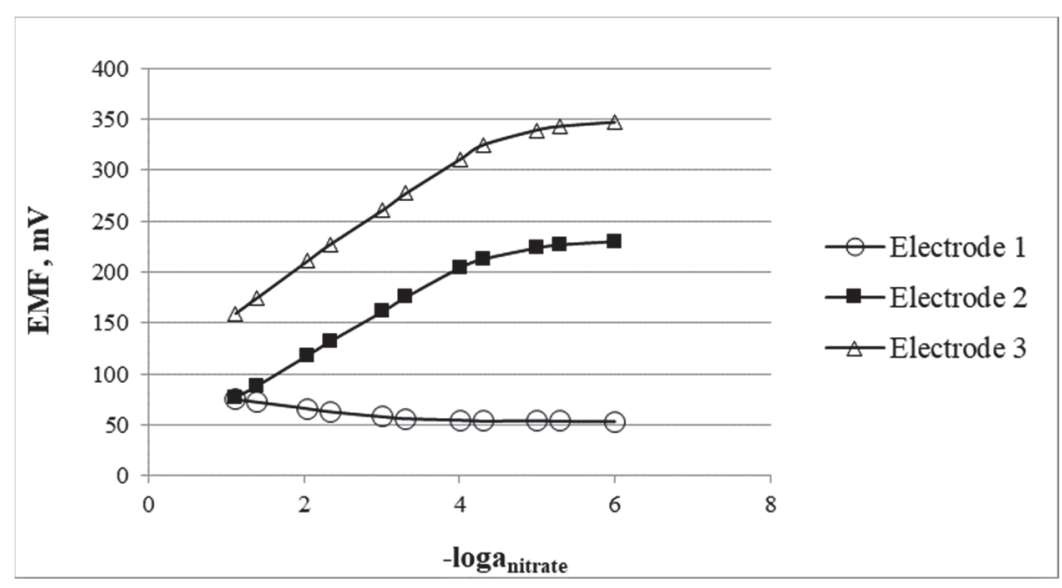

Figure 1. Potentiometric responses of studied electrodes determined in $\mathrm{NaNO}_{3}$ solution

\subsection{Selectivity study for prepared electrode}

The selectivity behavior is very important characteristic of any ion-selective electrode. It determines feasibility of a reliable measurement in the real sample. The selectivity of the studied sensors was evaluated by establishing their selectivity coefficients in reference to interfering ions. The selectivity coefficients were determined by the separate solution method (SSM) (by extrapolating the response functions to $a_{i}=a_{j}=1 \mathrm{~mol} \mathrm{~L}^{-1}$ ) (Fibbioli et al. 2000). The obtained values are listed in Table 3 where it can be seen that proposed electrode exhibits good selectivity to sulfate, acetate, carbonate, dihydrogen phosphate, fluoride and chloride ions. For nitrite and bromide ions, $\log \mathrm{K}^{\mathrm{pot}} \mathrm{X} / \mathrm{nitrate}>-2$. These ions can interfere the nitrate measurement if their concentration is high. In the case of samples such as natural water samples, in which they are present in trace levels, such interferences are negligible.

Table 3. Values of selectivity coefficients for electrode no.3

\begin{tabular}{|c|c|}
\hline $\mathrm{ION}$ & $\log K_{N O_{3}^{-} / X^{n-}}^{\text {pot }}$ \\
\hline $\mathrm{H}_{2} \mathrm{PO}_{4}^{-}$ & -4.2 \\
\hline $\mathrm{SO}_{4}{ }^{2-}$ & -4.1 \\
\hline $\mathrm{CO}_{3}^{2-}$ & -3.9 \\
\hline $\mathrm{CH}_{3} \mathrm{COO}^{-}$ & -3.5 \\
\hline $\mathrm{F}^{-}$ & -3.3 \\
\hline $\mathrm{Cl}^{-}$ & -2.1 \\
\hline $\mathrm{NO}_{2}^{-}$ & -1.4 \\
\hline $\mathrm{Br}^{-}$ & -0.6 \\
\hline
\end{tabular}

\subsection{Reversibility of the electrode potential for prepared electrode}

The reversibility of the electrode response is one of the most important parameter in analytical application point of view. In order to test the reversibility of the potential, the studied electrode was immersed in $1 \times 10^{-3} \mathrm{~mol} \mathrm{~L}^{-1} \mathrm{NaNO}_{3}$ solution for 5 minutes and next in $1 \times 10^{-4} \mathrm{~mol} \mathrm{~L}^{-1} \mathrm{NaNO}_{3}$ solution for the same period. 
This operation was repeated four times. The mean values of potential obtained from four measurements were $311.6 \pm 2.3$ and $260.1 \pm 1.5 \mathrm{mV}$ for $1 \times 10^{-4}$ and $1 \times 10^{-3} \mathrm{~mol} \mathrm{~L}^{-1}$ of $\mathrm{NO}_{3}{ }^{-}$ions solutions, respectively. The relative standard deviation in the potential measurement was 0.7 and $0.6 \%$. Such values proved that electrode is characterized by good potential reversibility.

\section{CONCLUSIONS}

Under given experimental conditions for $\mathrm{V}(\mathrm{V})$ voltammetric determination, the measurements can be performed in the presence of Brij-35 at given concentrations, without any interfering effects. However, other tested compounds which showed certain or total interfering effects need to be eliminated for successful $\mathrm{V}(\mathrm{V})$ quantitative determination. The results showed that used resins can decrease or eliminate interfering effect of surface active substances, but they are not appropriate for humic and fulvic acids under these experimental conditions.

Nitrate potentiometric sensor with solid contact was successfully developed. Proposed sensor exhibits good analytical parameters which are sufficient for nitrate determination in natural waters. Moreover it is simple to construct and easy to operate. Its significant advantage is the possibility to use directly in field measurements, in continuous mode measurements and in small laboratories that have no expensive equipment and highly qualified staff.

\section{ACKNOWLEDGMENTS}

The research have been carried out during Short Term Scientific Mission of dr Mersiha SULJKANOVIĆ. The STSM was realized in the frame of COST Action CA 16215: "European network for the promotion of portable, affordable and simple analytical platforms".

Mersiha SULJKANOVIĆ thanks to her hosts at the Department of Analytical Chemistry and Instrumental Analysis: dr Malgorzata Grabarczyk and dr Cecylia Wardak and also the Faculty of Chemistry of Maria Curie Sklodowska University for the invitation and opportunity for participating in research.

\section{REFERENCES}

Cattrall R.W, Freiser H (1971) Coated wire ion selective electrodes. Anal Chem 43: 1905-1906

Fibbioli M, Morf W.E, Badertscher M, De Rooij N.F, Pretsch E (2000) Potential drifts of sol-id-contacted ionselective electrodes due to zero-current ion fluxes through the sensor membrane. Electroanalysis 12: 1286-1292

Grabarczyk M, Wasąg J (2016) Application of a lead film electrode in adsorptive stripping voltammetry for the determination of indium trace in water samples. Journal of the Electrochemical Society 163: H465-H468

Grabarczyk M, Wasąg J (2015) Adsorptive cathodic stripping voltammetric method for determination of gallium using an in situ plated lead film electrode. Electroanalysis 27: 2596-2600

Hauser P.C, Chiang D.W.L, Wright G.A (1995) A potassium-ion selective electrode with valinomycin based poly(vinyl chloride) membrane and a poly(vinyl ferrocene) solid contact. Anal Chim Acta 302: 241-248

Hulanicki A, Trojanowicz M (1976) Calcium-selective electrodes with PVC membranes and solid internal contacts. Anal Chim Acta 87: 411-417

Mampuru L. A, Panichev N. A, Ngobeni P, Mandiwana K. L, Kalumba M. M (2015) Determination of leachable vanadium (V) in sediment. S Afr J Chem 68: 57- 60

McKnight, G. M, Duncan, C. W, Leifert C, Golden M. H (1999) Dietary nitrate in man: friend or foe? Brit J Nutr. 81: 349-358

Plaza S, Szigeti Z, Geisler M, Martinoia E, Aeschlimann B, Günther D, Pretsch E (2005) Potentiometric sensor for the measurement of $\mathrm{Cd}^{2+}$ transport in yeast and plants. Anal Biochem 347: 10-16

Settle F (1997) Handbook of Instrumental Techniques for Analytical Chemistry. National Science Foundation, Arlington

Sutter J, Lindner E, Gyurcsányi R. E, Pretsch E (2004) A polypyrrole-based solid-contact $\mathrm{Pb}^{2+}$-selective PVCmembrane electrode with nanomolar detection limit. Anal Bioanal Chem 380: 7-14

Wardak C (2014) Solid contact $\mathrm{Zn}^{2+}$-selective electrode with low detection limit and stable and reversible potential Cent Eur J Chem 12: 354-364

Wardak C (2012) A comparative study of cadmium ion-selective electrodes with solid and liquid inner contact. Electroanalysis 24: 85-90

Wasąg J, Grabarczyk M (2016) A fast and simple voltammetric method using a lead film electrode for determination of ultra-trace concentration of titanium in environmental water samples. Journal of the Electrochemical Society 163: H1076-H1080

Xiao X, Yang M, Guo Z, Jiang Z, Liu Y, Cao X (2015) Soil vanadium pollution and microbial response characteristics from stone coal smelting district. Trans Nonferrous Met Soc China 25: 1271-1278

Zosky C (2007) Handbook of Electrochemistry. Elsevier, Amsterdam 